\title{
Natural Cooccurrence of Deoxynivalenol and Nivalenol, Trichothecene Mycotoxins, in Commercial Foods*
}

\author{
(Received April 30, 1983)
}

\author{
Takumi Yoshizawa and Hiroko Hosokawa \\ (Department of Food Science; Faculty of Agriculture, \\ Kagawa University: Miki-cho, Kita-gun, Kagawa, Japan)
}

\begin{abstract}
Key words: trichothecenes; mycotoxin, deoxynivalenol; nivalenol; mass fragmentography; GC-MS analysis; commercial foods; natural occurrence; parched-barley flour
\end{abstract}

\section{Introduction}

During cultivation of wheat and barley in a crop field, field fungi, Fusarium graminearum (the imperfect stage of Gibberella zeae), often invade the plants, resulting in contamination of the harvested cereals by Fusaria mycotoxins. In the previous papers ${ }^{1-4)}$, the authors described the frequent natural occurcence of trichothecene mycotoxins, deoxynivalenol and nivalenol, in freshly harvested wheat and barley grains in Japan, and it was also proposed that these trichothecenes found in the cereals may be produced before harvest by different strains of Fusarium graminearum producing deoxynivalenol or nivalenol ${ }^{5}$.

It is likely that these trichothecenes contaminate certain foodstuffs made from the above cereals. However, the natural contamination of trichothecenes in foods has not been investigated. In this paper, we wish to describe the chemical analysis of deoxynivalenol and nivalenol in commercial parchedbarley flours ("Mugi-kogashi" or "Hattaiko" in Japanese).

\section{Materials and Methods}

Commercial samples of parched-barley flours were purchased at local markets in Kagawa, Ehime and Kumamoto prefectures.

A sample $(50 \mathrm{~g})$ was extracted with methanol-water $(150+50 \mathrm{ml})$ followed by filtration. The filtrate was defatted with $n$-hexane, concentrated and chromatographed successively

\footnotetext{
* Studies on the Toxic Substances in Infected Cereals (X)
}

on XAD-2 and Florisil columns according to Kamimura's method ${ }^{6}$ with some modifications. Thereafter, the extract was applied to a Sep-Pak $C_{18}$ cartridge and eluted with $2 \mathrm{ml}$ of $30 \%$ methanol in water. After concentration of the eluate, an aliquot of the residue was treated with a mixture of trimethylsilylimidazole-bis (trimethylsilyl)acetamide-trimethylchlorosilane $(3: 3: 2)$ and quantitated by mass fragmentography using a Hitachi M-80A mass spectrometer. Analytical conditions were as follows: $1 \mathrm{~m} \times 3$ $\mathrm{mm}$ id. glass column packed with $3 \% \mathrm{OV}-17$ on 80-100 mesh Chromosorb W (AW-DMCS), column temperature $270^{\circ} \mathrm{C}$, helium flow rate $28 \mathrm{ml} / \mathrm{min}$, ion source temperature $185^{\circ} \mathrm{C}$, ionizing voltage $20 \mathrm{eV}$, total emission $110 \mu \mathrm{A}$, multiplier gain $1.4 \mathrm{kV}$, scan rate $m / z 1-1500$ for $8 \mathrm{sec}$, vacuum $3 \times 10^{-7}$ torr. Fragment ions monitored were $m / z 512\left(\mathrm{M}^{+}\right)$, and $497\left(\mathrm{M}^{+}\right.$$\mathrm{CH}_{3}$ for deoxynivalenol, and $m / z 482\left(\mathrm{M}^{+}-110\right)$ and 413 for nivalenol.

\section{Results and Discussion}

The cleanup procedure using $\mathrm{XAD}$ resin and Florisil columns has been adopted successfully for the analysis of naturally occurring trichothecenes in several cereal grains ${ }^{4,7.8)}$. After the extraction and cleanup of parchedbarley flours, we observed interference with the deoxynivalenol peak on gas liquid chromatography with electron capture detector (GLC-EC) by a concomitant peak, and hence the lower limit of detection by GLC-EC was estimated to be around $100 \mathrm{ppb}$. On the other hand, the nivalenol peak was unaffected 

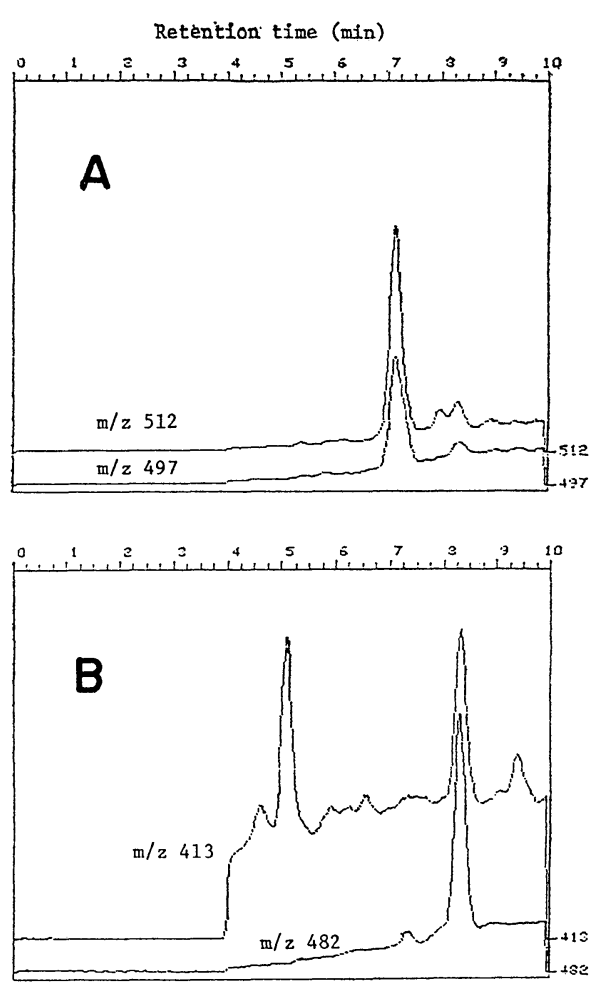

Fig. 1. GC-MS (mass fragmentography) at $\mathrm{m} / \mathrm{z}$ 512 and 497 for deoxynivalenol trimethylsilyl ether (A), and at $m / z 482$ and 413 for nivalenol trimethylsilyl ether (B) from the extract of naturally contaminated parchedbarley flour

by any interfering peak. The percentage recovery of these mycotoxins ranged from 75 to $80 \%$ at a level of $100 \mathrm{ppb}$, as measured by GLC-EC.
Fig. 1 shows a typical mass-fragmentogram of the extract of parched-barley flour sample. The fragment ions monitored at $m / z 512$ and 497 for the trimethylsilyl ether of deoxynivalenol $\left(t_{R}, 6.9 \mathrm{~min}\right)$ and at $m / z 482$ and 413 for that of nivalenol $\left(t_{R}, 8.0 \mathrm{~min}\right)$ gave satisfactory results. By this method, as little as $10 \mathrm{ppb}$ of the toxins can be detected.

Table 1 shows the concentrations of deoxynivalenol and nivalenol found in the parched-barley flours, as measured by mass fragmentography. Both trichothecenes were detected in all samples tested at levels ranging from 27 to $85 \mathrm{ppb}$ for deoxynivalenol, and from 37 to $190 \mathrm{ppb}$ for nivalenol. In sample numbers $46,47,53$ and 54 , these toxins were also detected by GLC-EC. With both these toxins, the values at the two ions were similar, and the coefficients of variation ranged from 6.4 to $9.4 \%$ for deoxynivalenol and from 3.8 to $12.3 \%$ for nivalenol.

In order to confirm the presence of these trichothecenes, the mass spectrum was taken at the peak corresponding to the individual toxin. As shown in Fig. 2, each spectrum shows diagnostic fragments due to the trimethylsilyl ether of deoxynivalenol or nivalenol.

To our knowledge, this is the first report on the natural cooccurrence of trichothecene mycotoxins, deoxynivalenol and nivalenol, in commercial foodstuffs. From the viewpoint of potential risk to human health, further extensive studies are required to clarify the mycotoxins contamination level in various foodstuffs made from domestic wheat and

Table 1. GC-MS Analysis of Deoxynivalenol and Nivalenol in Commercial Samples of Parched-barley Flours

\begin{tabular}{|c|c|c|c|c|c|c|}
\hline \multirow{3}{*}{$\begin{array}{c}\text { Sample } \\
\text { No. }\end{array}$} & \multicolumn{6}{|c|}{ Trichothecene level (ppb) analyzed at the indicated ion } \\
\hline & \multicolumn{3}{|c|}{ Deoxynivalenol } & \multicolumn{3}{|c|}{ Nivalenel } \\
\hline & $m / z 512$ & $m / z 497$ & Avg. & $m / z 482$ & $m / z 413$ & Avg. \\
\hline 45 & 25 & 29 & 27 & 41 & 32 & 37 \\
\hline 46 & 66 & 75 & 71 & 150 & 139 & 145 \\
\hline 47 & 59 & 70 & 65 & 74 & 88 & 81 \\
\hline 51 & 25 & 29 & 27 & 47 & 41 & 44 \\
\hline 53 & 77 & 93 & 85 & 199 & 181 & 190 \\
\hline 54 & 44 & 51 & 48 & 84 & 94 & 89 \\
\hline
\end{tabular}


RBP- $53 / 182$

SAMPLE NO.: IOI SCAN NO.:80-178 RT(MIN.): 6.9

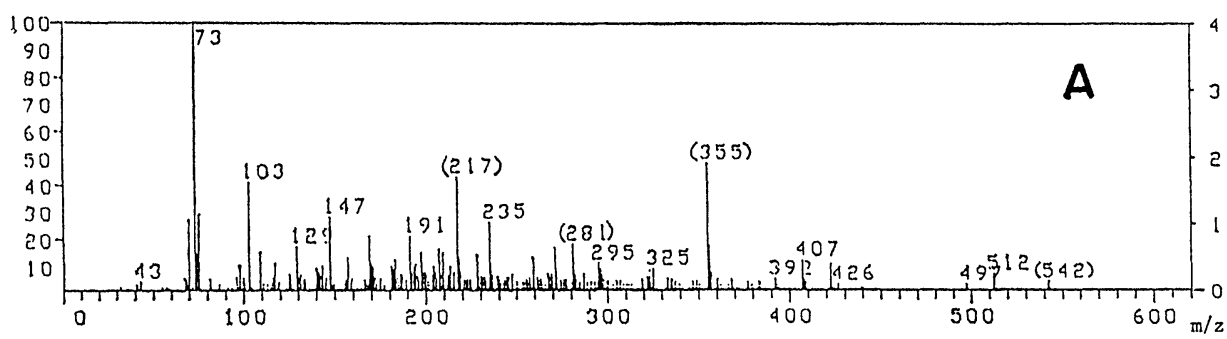

REP- $\$ 3 / 1,85$

SAMPLE NO: : 101 SCAN NO.: 93-178 RT(MIN.): 8.0

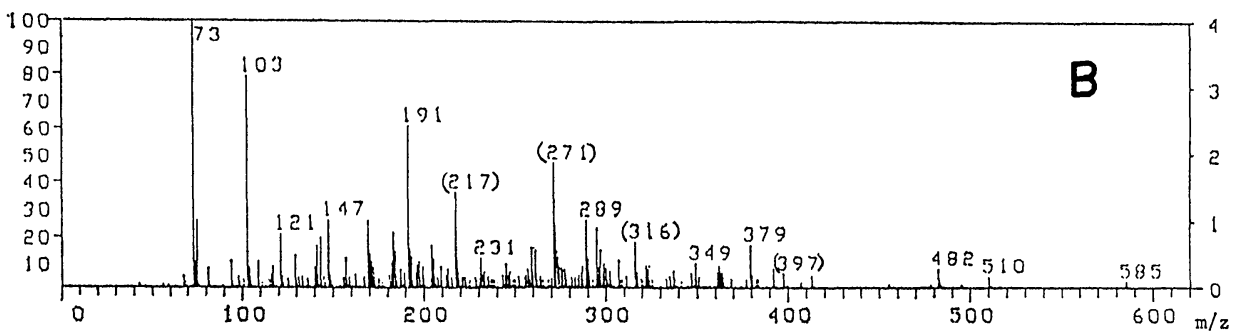

Fig. 2. Mass spectra of trimethylsilyl ethers of deoxynivalenol (A) and nivalenol (B) found in naturally contaminated parched-barley flour Fragment ions in parentheses were derived from impurities.

barley.

\section{Acknowledgement}

The authors express their thanks to $\mathrm{K}$. Shizukuishi, Naka Works, Hitachi Ltd., for the GC-MS analysis. This research was supported in part by a Grant-in-Aid for Cancer Research (57-35) from the Ministry of Health and Welfare, Japan.

\section{References}

1) Morooka, N., Uratsuji, N., Yoshizawa, T., Yamamoto, H.: J. Food Hyg. Soc. Japan 13, 368 (1972).

2) Yoshizawa, T., Tsuchiya, Y., Teraura, M., Morooka, N.: Proc. Jpn. Assoc. Mycotoxicol. 2, 30 (1976).
3) Yoshizawa, T.: ibid. 8, 6 (1978).

4) Yoshizawa, T.: "Trichothecenes-Chemical, Biological and Toxicological Aspects", edited by Ueno, Y., p. 197 (1983), Kodansha Ltd., Tokyo, Japan.

5) Yoshizawa, T., Matsuura, Y., Tsuchiya, Y., Morooka, N., Ichinoe, M., Kurata, H.: J. Food Hyg. Soc. Japan 20, 21 (1979).

6) Kamimura, H., Nishijima, M., Saito, K., Takahashi, S., Ibe, A., Ochiai, S., Naoi, Y.: ibid. 19, 443 (1978).

7) Kuroda, H., Mori, T., Nishioka, C., Okasaki, H., Takagi, M.: ibid. 20, 137 (1979).

8) Kamimura, H., Nishijima, M., Yasuda, K., Saito, K., Ibe, A., Nagayama, T., Ushiyama, H., Naoi, Y.: J. Assoc. Off. Anal. Chem. 64, 1067 (1981). 